\title{
Análisis de suspensiones de materiales de cambio de fase (PCM) como fluido caloportador y material de almacenamiento térmico
}

\author{
Mónica Delgado Gracia \\ GITSE (Grupo de Ingeniería Térmica y Sistemas Energéticos) \\ Instituto de Investigación en Ingeniería de Aragón (I3A). \\ Universidad de Zaragoza, Mariano Esquillor s/n, 50018, Zaragoza, Spain. \\ Tel. +34-876555584, e-mail: monica@unizar.es
}

\begin{abstract}
El trabajo se centra principalmente en el análisis experimental de suspensiones de materiales de cambio de fase microencapsulado para su uso como fluido caloportador y material de almacenamiento térmico.
\end{abstract}

\section{Estructura de la investigación}

El desarrollo de la tesis doctoral que aquí se presenta, está vinculado al disfrute de una ayuda EPIF, concedida por el Vicerrectorado de Investigación de la Universidad de Zaragoza. El trabajo se ha desarrollado en el marco de dos proyectos CYCIT del Plan Nacional de I+D+i y de un tercer proyecto OTRI con una empresa privada. La investigación realizada acerca de las suspensiones de PCM se compone de 3 grandes bloques: 1) estado de la tecnología; 2) caracterización experimental; 3) estudio de posibles aplicaciones y comparación frente a sistemas tradicionales con el PCM macroencapsulado.

\section{Estado de la tecnología}

Aunque la microencapsulación de PCM y su posterior suspensión en agua se trata de una tecnología reciente, el volumen de literatura comienza a ser significativo. La revisión bibliográfica de más de 80 referencias llevada a cabo en el marco de esta tesis, ha sintetizado en tablas la información y conclusiones extraidas de los trabajos previos a esta tesis, prestando gran atención al fenómeno de transferencia de calor. Del análisis de los estudios previos no se puede extraer una conclusión evidente sobre si el uso de estas suspensiones de PCM supone una mejora en el fenómeno de transferencia de calor, frente al caso base del agua. Es por este motivo que se planteó la necesidad de diseñar una instalación experimental que permita el estudio de este fenómeno.

\section{Caracterización experimental}

Determinación de propiedades termofísicas

Se ha llevado a cabo una búsqueda exhaustiva de suspensiones de PCM en el mercado comercial, universidades y centros de investigación. Entre las muestras recopiladas, se han determinado las curvas de entalpía-temperatura, y las curvas conductividad térmica-temperatura. Dentro de la dificultad que conlleva el análisis de estos materiales donde los métodos convencionales de análisis térmico presentan inconvenientes, en este trabajo cabe destacar la aportación de la medida de la conductividad térmica en función de la temperatura en fase líquida.

\section{Determinación de propiedades reológicas}

Se ha llevado a cabo también la caracterización reológica de las suspensiones de PCM candidatas, a partir de un reómetro de esfuerzo controlado. En concreto se han determinado las curvas de Viscosidad-Velocidad de Cizalla-Temperatura, obteniendo los modelos de comportamiento de estas suspensiones de PCM.

Además se ha propuesto una primera metodología para la medida de la viscosidad de PCM en estado fundido, para la caracterización del fenómeno de convección natural en el seno del PCM. Este trabajo fue realizado durante una estancia de investigación en el Instituto Fraunhofer ISE de Alemania. Este trabajo es parte del trabajo de la COST Action TU0802 y de la Task 42-Annex 24 de la Agencia Internacional de la Energía. Uno de sus objetivos es el desarrollo de metodologías estandarizadas para caracterizar el PCM de forma precisa y reproducible.

\section{Estabilidad y compatibilidad}

Se ha analizado la estabilidad física de estas suspensiones de PCM, en cuanto a los problemas de estratificación del PCM en suspensión, y la 
ruptura de las microcápsulas tras sufrir ciclados termo-mecánicos.

En cuanto a los problemas de estratificación, en este caso problemas de cremado, se han aplicado diferentes criterios reológicos de estabilidad encontrados en la literatura y se han relacionado con los procesos de desestabilización observados en las muestras. Las correlaciones obtenidas pueden servir de guía para que el fabricante reformule la suspensión y lograr así una mejor estabilidad física. Además se puede estimar la duración del proceso de desestabilización sin necesidad de tener que esperar a la completa desestabilización.

En cuanto a la ruptura de las microcápsulas de PCM, se ha observado su morfología con un microscopio electrónico de barrido de tipo ambiental, observándose en alguna de las muestras la ruptura de las microcápsulas. Además se ha analizado la posible contaminación microbiana en las muestras analizadas. Una de las muestras que había estado almacenada durante un periodo de 12 meses contenía hongos filamentosos y bacterias ambientales, tipo sarcinas o levaduras. Se descarta la posibilidad del hongo Aspergillus y de la bacteria Legionella.

En cuanto a los estudios de compatibilidad, como el objetivo de la tesis es comparar los sistemas de almacenamiento térmico con suspensiones de PCM frente a sistemas tradicionales donde el PCM es macroencapsulado en diferentes geometrías contenedoras, se ha analizado la migración de PCM a través de la pared plástica de cápsulas esféricas. Se ha observado una pérdida de masa a través del plástico de la esfera en el caso de los PCMs de carácter orgánico. Respecto a la compatibilidad en el caso de las suspensiones de PCM, se han analizado los posibles fenómenos de corrosión, al estar en contacto tales fluidos con aleaciones metálicas típicas en instalaciones térmicas. Se ha observado corrosión en el cobre y aluminio.

\section{Estudio de aplicaciones}

Se ha diseñado, puesto en marcha y validado una instalación experimental que permite analizar de forma precisa y rigurosa el fenómeno de transferencia de calor y de la mecánica de fluidos, así como la viabilidad técnica de estas suspensiones de PCM. Para la medida de las temperaturas de pared, magnitud clave para la evaluación de la transferencia de calor, se ha propuesto un modelo empírico de corrección de temperaturas para tratar posibles desviaciones.

A partir de los resultados de los ensayos realizados, en las suspensiones de PCM analizadas se ha observado que para una misma energía térmica transportada, el trabajo de bombeo puede reducirse hasta cuatro veces frente al caso del agua. El rango de temperaturas de operación de la suspensión de PCM se debe ajustar con el rango de temperaturas de cambio de fase. Es una de las suspensiones de PCM analizadas, con una fracción másica del 20\% de microcápsulas, la que presenta un mejor comportamiento térmico para su uso como fluido caloportador, se han determinado mejoras en el coeficiente de transferencia de calor por convección de hasta el 45\% respecto al agua.

Además se han analizado numéricamente tres depósitos de almacenamiento térmico de energía de baja temperatura (almacenamiento entre 5 y $13^{\circ} \mathrm{C}$ ), para su uso en aplicaciones de refrigeración solar. Se ha analizado en los tres casos el mismo tamaño de depósito. El primero conteniendo esferas de PCM y realizando el intercambio de calor con agua (se ha analizado según el tamaño de las cápsulas esféricas). El segundo conteniendo un serpentín helicoidal por el que circula agua, con suspensión de PCM como material de almacenamiento. Y ya el tercero que sería como el segundo pero conteniendo en esta ocasión agua. La densidad energética del depósito con la suspensión de PCM es 1,35 veces mayor que la del depósito con esferas de menor tamaño (de $0.03 \mathrm{~m}$ ) y 2,5 veces mayor que la del depósito con agua. Son el depósito con esferas de $0.03 \mathrm{~m}$ y el depósito con la suspensión de PCM los que suministran una mayor potencia durante un mayor tiempo. El resto de sistemas disminuyen su potencia hasta valores por debajo de la mitad.

\section{Conclusiones y difusión de resultados}

Se ha planteado una metodología rigurosa para el análisis de suspensiones de PCM como nuevo fluido caloportador y nuevo material de almacenamiento d energía térmica. Durante el desarrollo de este trabajo se ha realizado un esfuerzo importante en acudir a foros científicos para conocer la evolución de la tecnología y difundir los resultados más relevantes obtenidos. Se han publicado 5 artículos en revistas científicas internacionales indexadas en la base JCR y se ha presentado un total de 9 trabajos en congresos tanto nacionales como internacionales. 